\title{
An update on sphingosine-1-phosphate and other sphingolipid mediators
}

\author{
Henrik Fyrst ${ }^{1}$ and Julie D. Saba ${ }^{1,}{ }^{*}$ \\ ${ }^{1}$ Center for Cancer Research, Children's Hospital Oakland Research Institute, Oakland, CA \\ 94609
}

\section{Abstract}

Sphingolipids comprise a complex family of naturally occurring molecules that are enriched in lipid rafts and contribute to their unique biochemical properties. Membrane sphingolipids also serve as a reservoir for bioactive metabolites including sphingosine, ceramide, sphingosine-1phosphate and ceramide-1-phosphate. Among these, sphingosine-1-phosphate has emerged as a central regulator of mammalian biology. Sphingosine-1-phosphate is essential for mammalian brain and cardiac development and maturation of the systemic circulatory system and lymphatics. In addition, sphingosine-1-phosphate contributes to trafficking and effector functions of lymphocytes and other hematopoietic cells and protects against various forms of tissue injury. However, sphingosine-1-phosphate is also an oncogenic lipid that promotes tumor growth and progression. Recent preclinical and clinical investigations using pharmacological agents that target sphingosine-1-phosphate, its receptors, and the enzymes required for its biosynthesis and degradation demonstrate the promise and potential risks of modulating sphingosine-1-phosphate signaling in treatment strategies for autoimmunity, cancer, cardiovascular disease and other pathological conditions.

\section{Introduction}

Sphingolipids are present in all eukaryotic cells where they contribute to membrane biology and signaling events that influence cell behavior and function ${ }^{1,2}$. Sphingolipid metabolites including ceramide, sphingosine, ceramide-1-phosphate (C1P) and sphingosine-1-phosphate (S1P) have emerged as bioactive signaling molecules that regulate cell movement, differentiation, survival, inflammation, angiogenesis, calcium homeostasis and immunity. New insights regarding sphingolipids have been gained through identification and cloning of genes encoding related enzymes, transporters and receptors and through development and use of pharmacological agents that modulate the activities of these proteins. Pub-Med citations for S1P alone number more than 2400, and novel paradigms emerge within the field on a regular basis. After the recognition in $2002^{3,4}$ that the active form of the immunomodulatory agent FTY720 binds to four of the five known S1P receptors, there has been a groundswell of research activity elucidating the fundamental role of S1P chemotactic gradients in immune cell trafficking. In addition, recent studies have clarified mechanisms by which S1P signaling contributes to embryogenesis, vascular biology, cardiovascular physiology, carcinogenesis, stress responses, and tissue regeneration. Based on these recent observations and the ever-changing armamentarium of pharmacological agents that modulate S1P metabolism and receptor activation, the possibilities of harnessing S1P signaling pathways for curative intervention are emerging. This review will highlight new

\footnotetext{
*Address correspondence to Julie D. Saba, Children's Hospital Oakland Research Institute, 5700 Martin Luther King Jr. Way, Oakland, CA 94609-1673. Tel: 510-450-7690. Fax: 510-450-7910. jsaba@chori.org.
} 
findings on S1P-mediated biology and will touch briefly upon other recently identified bioactive sphingolipid intermediates in this rapidly expanding field. For general background on membrane sphingolipids, ceramide and enzymes of sphingolipid metabolism, the reader is referred to several excellent reviews ${ }^{1,2,5-7}$.

\section{The sphingolipid metabolic pathway}

The de novo biosynthesis and metabolism of sphingolipids is depicted in Figure 1. Sphingolipid biosynthesis initiates in the endoplasmic reticulum (ER) where the ratelimiting first step is catalyzed by serine palmitoyltransferase (SPT) ${ }^{2}$. SPT is a heterotrimeric complex that is negatively regulated by Orm proteins which have been associated with predisposition to the development of asthma ${ }^{8,9}$. Ceramide and sphingoid bases formed through biosynthetic or recycling/degradation pathways can be phosphorylated at the sn1position by lipid kinases. The phosphorylated compounds can be dephosphorylated by specific and nonspecific lipid phosphatases. Alternatively, S1P can be irreversibly degraded by S1P lyase (SPL).

Cells maintain a dynamic balance of distinct sphingolipid metabolites, many of which are bioactive, with ceramide and sphingoid bases serving as activators of cell death pathways, whereas S1P and C1P primarily exert mitogenic effects. Altered regulation of the S1P/ ceramide ratio can lead to an imbalance in the "sphingolipid rheostat," through which these sphingolipid metabolites influence cell fate and tissue homeostasis. An extension of the rheostat notion whereby ceramide kinase (CERK) regulates a critical balance between ceramide and C1P has also been suggested ${ }^{10}$.

The sphingolipid rheostat is ultimately only one of multiple factors that determine cellular responses to bioactive sphingolipids, whose effects are modulated by their subcellular localization, cellular import/export, protein carrier binding, and receptor and target expression. In some cases, counteracting signals such as those emanating from pathways activated by different S1P receptor subtypes and tissue S1P gradients generated by the opposing actions of sphingosine kinase (SphK) and SPL weigh heavily in determining how sphingolipids will influence cell behavior. Thus, in lieu of the two-dimensional rheostat model, we favor a multidimensional "sphingodynamics" model to represent the complexity of sphingolipid-mediated biology as we now understand it (Figure 2).

\section{S1P metabolizing enzymes}

\section{Sphingosine kinases}

Two highly homologous sphingosine kinase isoenzymes, SphK1 and SphK2, have been characterized ${ }^{11-13}$. Both enzymes phosphorylate sphingosine and dihydrosphingosine, although SphK2 has broader substrate specificity, catalyzing phosphorylation of phytosphingosine and the sphingoid base analog FTY720. SphK1 promotes cell growth, whereas both overexpression and downregulation of SphK2 have been shown to inhibit cell growth and enhance apoptosis in different model systems. Despite these differences, the functions of SphK1 and SphK2 are at least partly redundant, since mice lacking either isoform maintain nearly normal S1P levels and lack severe phenotypes. In contrast, the SphK1/SphK2 double knockout mouse is embryonic lethal due to incomplete maturation of the vascular system and brain ${ }^{14}$. Both SphK isoforms have also been found within the centrosome, where it is suggested they may play a role in regulating spindle formation and mitosis ${ }^{15}$ (Figure 3).

SphK1 is the major enzyme responsible for S1P synthesis and as such is highly regulated at all stages of expression through a combination of epigenetic, transcriptional and post- 
translational mechanisms ${ }^{11}$. Membrane recruitment of SphK1, which is important in its activation, was recently found to be regulated by the $\mathrm{Ca}^{2+}$-myristoyl switch protein calcium and integrin-binding protein 1 (CIB1) ${ }^{16}$. SphK1-generated S1P has been implicated in many physiological and pathological processes, including the regulation of blood pressure and vascular permeability, carcinogenesis and allergic responses, as described in the related sections below.

In addition to its pharmacological role in activating FTY720 and overlapping functions with SphK1, SphK2 also appears to generate specific signaling pools of S1P. For example, SphK2-derived S1P has been implicated in uterine deciduation (shedding of endometrial tissue during menstruation), histone deacetylase-mediated transcriptional regulation (see below), macrophage polarization and tumor association, regulation of cytokine expression, and protection from ischemia-induced renal and cerebral tissue injury ${ }^{17-21}$. There is evidence that SphK2 also mediates effects independently of S1P. For example, SphK2 contains a BH3-domain that may be responsible for its induction of apoptosis in an S1P receptor-independent fashion that involves its direct interaction with Bcl-xL, release of cytochrome $\mathrm{c}$ and activation of caspase- $3^{22}$. A recent study revealed that the $\mathrm{N}$-terminus of SphK2 is cleaved in a caspase-1-dependent manner, leading to release of a truncated but enzymatically active SphK2 fragment from cells undergoing apoptosis ${ }^{23}$. Interestingly, the $\mathrm{N}$-terminus also contains a lipid-binding domain proposed to facilitate SphK2 translocation to the membrane and which would presumably be disrupted by caspase-mediated cleavage

${ }^{24}$. Finally, studies suggest that SphK2 may contribute to the regulation of CD4+ T cell responses to interleukin 2 in an S1P-independent manner ${ }^{25}$.

A viable mouse model lacking circulating S1P in the blood and lymphatics due to generalized SphK2 disruption and conditional disruption of SphK1 in blood stem cells, vasculature, liver and some additional tissues has been generated ${ }^{26}$. Aside from lymphopenia due to a trafficking defect, no other phenotype associated with this model has been described. This suggests that sphingosine kinase is not essential postnatally or that it is required in a limited number of tissues. Further examination of the "S1P-less" mouse model and of SphK1 and SphK2 knockout mice in post-natal life under different experimental conditions may uncover more subtle physiological functions of the sphingosine kinases and S1P. Conversely, strategies to selectively modulate catalytic and/or non-enzymatic activities of SphK1 and SphK2 may ultimately be useful in the treatment of diseases in which their functions are implicated.

\section{S1P phosphatases}

Several enzymes with lipid phosphatase activity can dephosphorylate S1P 27,28. SPP1 and SPP2 are differentially expressed sphingoid base-specific phosphatases located in the ER. SPP2 is expressed in embryonic mouse kidney and, in combination with SphKs, plays a role in regulating S1P levels in metanephric mesenchyme, thereby influencing branching morphogenesis during kidney development ${ }^{29}$. The SPPs may control the flow of sphingoid bases into different metabolic pathways, and SPP1 has been implicated in regulating ceramide levels in the ER, which affects transport of both ceramide and proteins from the ER to the Golgi apparatus ${ }^{30}$. SPP1 appears to gain access to extracellular S1P via its import into the cell by an ATP-binding cassette (ABC) transporter ${ }^{31}$. A combination of experimental results and the finding of altered SPP1 and SPP2 mRNA levels in various diseased tissues has implicated S1P phosphatases in the regulation of microvascular tone and the pathophysiology of inflammatory diseases, cancer and other conditions.

Alternatively, S1P and C1P can be dephosphorylated by a family of broad-specificity lipid phosphatases known as LPPs. As with the SPPs, ecto-LPP activity is involved in regulating 
extracellular S1P signaling and uptake, as well as the dephosphorylation of C1P and FTY720-phosphate ${ }^{32}$.

\section{S1P lyase}

S1P can be irreversible degraded by the intracellular protein S1P lyase (SPL) ${ }^{33}$. In this reaction, the sphingoid base is cleaved at position $\mathrm{C} 2,3$ yielding hexadecenal and ethanolamine phosphate. Murine SPL is ubiquitiously expressed with highest levels found in intestine, thymus and olfactory mucosa. However, we have also observed upregulation and activation of SPL in response to ischemia, radiation and chemical injury in other tissues (our unpublished data). Further, SPL has been implicated as a downstream target of PDGF signaling and was identified in a screen for nitrosylated proteins ${ }^{34,35}$. Together, these findings suggests that SPL may play a dynamic role in the response to tissue injury and that resting expression patterns of SPL expression may be misleading.

SPL knockout mice fail to survive beyond weaning. Anemia, myeloid cell hyperplasia and multiple congenital anomalies were observed in SPL null mice, including pathological lesions in the lung, heart, urinary tract, and bone ${ }^{36}$. These findings may be associated with the accumulation of long chain bases and ceramides, in addition to high and possibly cytotoxic levels of S1P in neurons and vital organs 37,38 .

SPL also appears to have an impact on global lipid metabolism. In Drosophila, SPL products were found to contribute to the formation of phosphatidylethanolamine, which is essential for regulated processing of sterol regulatory element-binding proteins (SREBP) and the transcriptional control of lipid biosynthesis ${ }^{39}$. Tissues of SPL null mice exhibited changes in expression of PPAR $\gamma$ and other genes involved in lipid metabolism, and elevated diacylglycerol, triacylglycerol, phospholipids and total and esterified cholesterol levels were detected in plasma and liver ${ }^{38}$. Despite these findings, SPL knockout mice were lean. The fatty liver, elevated triglycerides and striking lack of adipose tissue in SPL knockout mice are reminiscent of the human lipodystrophies, a collection of diseases marked by lipid metabolic disturbances and deficient adipose tissue. Further study will be required to determine whether these features are due to failure of adipocyte development and differentiation, increased adipocyte destruction, or a qualitative defect in adipocytes or other metabolic functions. While much remains to be determined about the etiology of the SPL null mouse phenotype, these findings suggest that sphingolipids may be important regulators of global lipid homeostasis and may play a part in the development of metabolic syndromes, as previously proposed ${ }^{40}$.

In addition to regulating S1P pools and upstream sphingolipid intermediates, SPL exerts effects through its products, such as the requirement in Leishmania major for ethanolamine phosphate to grow vegetatively and infect humans ${ }^{41}$. SPL-catalyzed production of the reactive molecule hexadecenal may also have biological import, possibly via formation of DNA or protein adducts, although this remains a relatively unexplored area.

\section{S1P receptors and transporters}

Five mammalian $\mathrm{G}$ protein-coupled S1P receptors $\left(\mathrm{S}_{1} \mathrm{P}_{1-5}\right)$ have been identified. The deployment of receptor agonists, antagonists and murine receptor knockout models combined with the characterization of specific receptor expression patterns is helping to clarify the unique biological functions of each receptor subtype ${ }^{42-44}$. S1P receptor signaling contributes to a wide range of physiological functions, including maturation of the vascular system, blood vessel permeability and pathological angiogenesis $\left(\mathrm{S}_{1} \mathrm{P}_{1,2}\right)$, blood pressure regulation, histamine clearance, and recovery from anaphylaxis $\left(\mathrm{S}_{1} \mathrm{P}_{2}\right)$, immune cell egress from tissue compartments $\left(\mathrm{S}_{1} \mathrm{P}_{1,5}\right)$, inner ear development $\left(\mathrm{S}_{1} \mathrm{P}_{2}\right)$, pulmonary epithelial 
integrity $\left(\mathrm{S}_{1} \mathrm{P}_{3}\right)$, perinatal survival $\left(\mathrm{S}_{1} \mathrm{P}_{2,3}\right)$, hematopoietic, vascular and stem cell survival and cytokine production $\left(\mathrm{S}_{1} \mathrm{P}_{1,4}\right)$, and neuronal functions such as axon guidance and oligodendrocyte survival $\left(\mathrm{S}_{1} \mathrm{P}_{5}\right)^{44-48}$. The $\mathrm{S} 1 \mathrm{P}$ receptors are regulated through distinct mechanisms, such as transcriptional regulation of $\mathrm{S}_{1} \mathrm{P}_{1}$ by Krüppel-like factor 2 and $\mathrm{S}_{1} \mathrm{P}_{1}$ 's exquisite sensitivity to ligand-induced internalization ${ }^{49}$, as compared to the transcriptional regulation of $\mathrm{S} \mathrm{P}_{5}$ by T-bet and its lack of agonist-mediated downregulation ${ }^{50}$. The expression, subcellular localization and membrane context of specific S1P receptors on different static and migrating cell populations are major determinants in their responses to S1P. S1P receptors could also potentially emit signals in the absence of S1P ligand, as has been described for netrins. The G protein partners, downstream signaling events and biological functions of the S1P receptors have been reviewed extensively ${ }^{51,52}$. Therefore, individual receptor functions will be discussed further only within the context of specific diseases in the sections below.

Several proteins have been implicated in cellular export of S1P. Members of the ABC transporter family have been linked to the release of S1P from blood cells, which are the primary source of blood S1P 53,54. The zebrafish spinster 2 (Spns2) gene (named after the Drosophila gene Spin with which it is homologous) was identified as a mutant exhibiting cardia bifida, a congenital heart malformation caused by failure of cells of the cardiogenic mesenchyme to migrate to the midline during cardiac morphogenesis. The cardia bifida phenotype had been previously reported in zebrafish S1P receptor mutants, thereby leading to identification of the multipass transmembrane Spns2 protein as an S1P transporter ${ }^{55,56}$. Interestingly, Drosophila Spin mutants exhibit neurodegeneration and accumulation of lipofuscin-like materials in the central nervous system ${ }^{57}$, suggesting they may represent an invertebrate form of S1P sphingolipidosis.

The vertebrate S1P transporter and receptor mutant phenotypes raise the possibility that S1P signaling or transport defects may underlie a subset of human congenital cardiac anterior/ posterior segmental defects. Although the most severe of these (cardia bifida) would not allow survival to parturition, more subtle defects could be compatible with life. S1P signaling may influence proteins involved in cardiac cell migration and possibly other critical events during development of the primitive heart tube. Elucidating such interactions may reveal the specific molecular mechanisms by which S1P contributes to cardiac and other developmental programs.

\section{Intracellular S1P signaling}

A variety of studies performed in organisms lacking identifiable S1P receptors show that disrupting S1P metabolism can result in marked changes in cell migration, $\mathrm{Ca}^{2+}$ mobilization, stress responses, endocytosis, tissue homeostasis, infectivity, viability and reproduction ${ }^{58}$. These effects could be explained by the direct interaction of S1P with intracellular targets. However, they could also be caused by altered membrane functions or other nonspecific effects of sphingolipids. Thus, the intracellular signaling function of S1P has remained a controversial issue.

An exciting recent study in mammalian cells has shown that SphK2 and its product S1P are assembled in corepressor complexes containing histone deacetylase 1 and 2 (HDAC1-2). Nuclear S1P-containing HDAC complexes prevent deacetylation of lysine residues within the histone tail, thereby affecting its DNA binding and resulting in upregulation of p21 and c-fos ${ }^{18}$ (Figure 3). This study demonstrates that intracellular S1P may act directly upon molecular targets in the nucleus to influence gene expression. This study raises many interesting questions, such as how SphK2 nuclear translocation is regulated, which genes are under the control of S1P-containing HDAC complexes, whether nuclear S1P receptors are 
involved in nuclear S1P-mediated events, and whether nuclear SphK/S1P contributes to epigenetic changes associated with cancer, development or other diseases 59,60 . It also suggests the interesting possibility that nuclear SphK2/S1P could provide a strategy to upregulate p21 and thereby promote apoptosis in p53-deficient cancer cells.

\section{S1P in invertebrate development}

Invertebrate models have also contributed to our understanding of the role of S1P in development, particularly with regard to S1P metabolism. Drosophila sphingosine kinase 2 (Sk2), dihydroceramide desaturase (ifc) and S1P lyase (Sply) mutants display non-lethal developmental defects and tissue degeneration in reproductive organs and flight muscles 33,61. Reproductive defects have also been observed in response to SPL knockdown in Caenorhabditis elegans ${ }^{33}$. A mutation in the Drosophila CERK gene was recently shown to be associated with photoreceptor degeneration ${ }^{62}$. In the context of developmental programs lacking obvious S1P receptors, these phenotypes most likely represent receptor-independent effects that may result when ceramide and/or other sphingolipid intermediates perturb membrane structure, calcium homeostasis and/or protein functions. However, aberrant signaling through as yet unrecognized primitive S1P-binding receptors also remains a possibility. Interestingly, developmental abnormalities observed in the female gonads of SPL mutant fruit flies and nematodes were recently found to be mirrored by similar defects in homozygous SPL knockout mice ${ }^{63}$. Further, S1P signaling contributes to mammalian muscle homeostasis and regeneration as it does in fruit flies ${ }^{64}$ (our unpublished observations). Thus, we suspect that some phenotypes associated with vertebrate and invertebrate sphingolipid mutant lines will prove to be harbingers of as yet undiscovered $\mathrm{S} 1 \mathrm{P}$ signaling roles in mammalian biology.

\section{S1P signaling and human disease}

\section{S1P and the hematopoietic/immune systems}

The lead observation that FTY720, a synthetic immunomodulatory agent modeled after the fungal toxin myriocin, is phosphorylated in vivo and induces lymphopenia by binding to S1P receptors has resulted in an extraordinary series of reports that have begun elucidating the role of S1P signaling in immunity 6566 . Many of the studies have been reviewed elsewhere 67-69. The collective work of many investigators has revealed that S1P signaling through its cognate receptors regulates T, B, natural killer (NK) and hematopoeitic stem cell trafficking through the generation of both systemic and localized chemotactic gradients (Figure 4).

In brief, a major S1P gradient is generated by erythrocyte SphK1, which is primarily responsible for the high blood levels of S1P, coupled with a thymic source of SPL that is likely of hematopoietic origin and serves as an S1P sink. As thymocytes reach maturity, they begin to express $\mathrm{S}_{1} \mathrm{P}_{1}$, which allows them to sense the gradient and move into the bloodstream. However, a local S1P gradient generated by SphK harbored in neural crestderived pericytes ensheathing blood vessels located at the corticomedullary junction is required to facilitate $\mathrm{T}$ cell egress into the circulation ${ }^{70}$.

Lymphocytes continually enter and exit lymph nodes (LN), wherein they may encounter antigen and become stimulated. Upon stimulation and in response to factors such as interferon, $\mathrm{T}$ cells express the activation marker CD69, which complexes with $\mathrm{S}_{1} \mathrm{P}_{1}$ and leads to its downregulation, thereby preventing $\mathrm{T}$ cell egress from the $\mathrm{LN}$. Once $\mathrm{S}_{1} \mathrm{P}_{1}$ is reexpressed, T (and B) cells move to the LN cortical sinus and the efferent lymphatics in response to a local S1P gradient generated by the lymphatic endothelium. The actions of

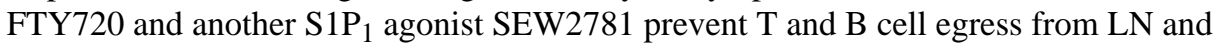
peyer's patches, whereas inhibition of SPL by 2-acetyl-4-tetrahydroxybutylimidazole (THI), 
deoxypyridoxine or the Lexicon Pharmaceuticals agent LX2931 eliminates the S1P gradient, with the same result. FTY720 and LX2931 are in clinical trials for autoimmune diseases including multiple sclerosis and rheumatoid arthritis. Considering the efficacy already shown by these compounds, and in light of earlier studies investigating the immunological actions of THI, they are likely to offer therapeutic value in a variety of disorders of immune disregulation and possibly in solid organ transplantation ${ }^{71,72}$.

Similar S1P-dependent mechanisms appear to be responsible for mediating hematopoietic progenitor cell (HPC) egress from bone marrow and the migration of other hematopoietic cell types ${ }^{73}$. For example, NK cells express both $\mathrm{S}_{1} \mathrm{P}_{1}$ and $\mathrm{S}_{1} \mathrm{P}_{5}$, which together contribute to the ability of NK cells to egress from bone marrow and $\mathrm{LNs}^{50}$. If $\mathrm{S}_{1} \mathrm{P}_{1}$ is such an efficient system for regulating immune responses, why are other S1P receptors needed on immune cells? The role of NK cells in tumor surveillance and innate immunity and other specific functions of non-lymphoid immune cells may be better served by independence from the sensitive regulatory feedback mechanisms that affect $\mathrm{S}_{1} \mathrm{P}_{1}$. As more specific reagents become available, the functions of other S1P receptors that may have been overshadowed by the profound interaction between FTY720 and $\mathrm{S}_{1} \mathrm{P}_{1}$ are likely to be uncovered.

In addition to these trafficking functions, S1P helps to regulate the "settling" of bone marrow-derived thymic progenitors (TCPs) in the thymus ${ }^{74}$. TCP homing is an oscillating process that requires interactions between thymic P-selectin-expressing endothelial cells and P-selectin ligand-expressing TCPs. Although the presence of early TCPs within the thymic cortex appears to be the major feedback signal regulating inflow of new TCPs, S1P signaling adds another layer of regulation by controlling endothelial expression of Pselectins. Interestingly, in addition to exhibiting a lymphocyte egress defect, SPL knockout mouse thymi have unexplained cortical destructive changes ${ }^{75}$. These changes could potentially be due to high thymic S1P levels, reduced P-selectin expression and defective progenitor homing. This is consistent with the finding that the SPL inhibitor DOP inhibits thymic receptivity to TCPs ${ }^{74}$.

Finally, S1P signaling has an impact on other hematopoietic cell functions, including the migration and functions of osteoclast precursors, hematopoietic stem cells, dendritic cells, mast cells, regulatory $\mathrm{T}$ cells, macrophages and pre-B cells ${ }^{67,76-80}$. These cumulative findings establish S1P as a major regulator of innate and adaptive immunity. They also raise new questions. For example, the cellular sources of SPL that produce S1P gradients, the role of S1P signaling in lymphocyte development, and how S1P signaling contributes to tissue gating and barrier functions remain poorly understood areas. Further, it will be important to establish whether S1P signaling defects are responsible for inborn or acquired immune diseases and to assess the long-term effects of pharmacological suppression of lymphocyte circulation on thymic education and peripheral lymphoid organ functions. These and other enigmas should become clear as investigators continue to exploit powerful experimental tools including conditional knockouts, highly specific agonists/antagonists, and specific cell labeling approaches. It is difficult to keep pace with the rapidly moving target of S1P in the immune system, and this review only captures a single frame in a complex and continuing story.

\section{S1P in cardiovascular disease and tissue injury}

S1P enhances mammalian cardiomyocyte survival during hypoxia and contributes to ischemic preconditioning and recovery from ischemia/reperfusion (I/R) injury ${ }^{81}$. These effects appear to be mediated through $\mathrm{S}_{1} \mathrm{P}_{1}$ activation and downstream signaling through Akt. I/R-induced infarction was augmented in hearts from $\mathrm{S}_{1} \mathrm{P}_{2} / \mathrm{S}_{1} \mathrm{P}_{3}$ double null mice as compared to control mice, suggesting that these receptors contribute to cardioprotection as 


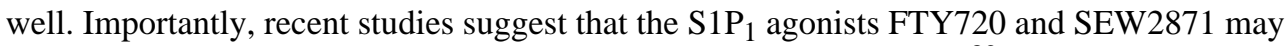
provide protection against stroke and ischemic injury in other tissues ${ }^{82}$.

SPL inhibition may serve as another strategy for mediating cardioprotection. Using an $e x$ vivo murine model of $\mathrm{I} / \mathrm{R}$, we have observed activation of SPL through a post-translational mechanism in ischemic hearts (our unpublished results). SPL-deficient mice and mice pretreated with THI exhibited reduced infarct size and improved functional recovery compared to controls. SPL inhibition also affords protection in murine LPS-induced acute lung injury models (personal communication, Viswanathan Natarajan). Together, these findings raise the possibility that S1P analogs and SPL inhibitors currently undergoing testing as immunomodulators may be further developed for cardioprotection, to prevent sepsis-related tissue injury, and for use in other clinical scenarios in which S1P has been implicated such as radioprotection and preservation of fertility ${ }^{83}$.

High density lipoprotein (HDL) is an important circulating lipoprotein complex which confers protection against atherosclerosis and heart disease. HDL along with albumin are major plasma carriers of S1P, and evidence suggests that many actions of circulating HDL are mediated through its cargo lipid, $\mathrm{S}_{\mathrm{P}} \mathrm{P}^{84}$. By carrying S1P to its receptors and facilitating S1P/S1P-receptor interactions, HDL stimulates endothelial nitric oxide production, vasodilation, cardioprotection and survival. These findings raise the exciting possibility that S1P receptor agonists may serve as HDL mimics.

\section{S1P and cancer}

In contrast to the protective role of S1P signaling in cardiovascular disease, S1P is a contributing factor in carcinogenesis. Overexpression of murine SphK1 in 3T3 cells induces transformation via a Ras-dependent signaling pathway ${ }^{85}$. Further, human SphK1 is upregulated in many cancers ${ }^{11}$. These findings demonstrate that $S p h K 1$ functions as an oncogene. Sphk1 upregulation often correlates with higher clinical grade and chemotherapy resistance, whereas inhibition of SphK activity increases apoptosis and autophagy in cancer cells. Additional studies implicate SphK1 in adhesion and migration of cancer cells, properties associated with metastatic potential. SphK1 appears to promote cancer growth via multiple mechanisms, including autocrine S1P signaling intrinsic to cancer cells, by promoting tumor angiogenesis, and by modulating the microenvironment. Importantly, sequestering S1P with a specific S1P monoclonal antibody blocks tumorigenesis and tumor angiogenesis in murine xenograft and allograft cancer models ${ }^{86}$. SphK1 is activated by many stimuli, which lead to its upregulation and/or membrane translocation. Its stable upregulation in cancer appears to occur at the transcriptional level in response to hypoxiainducible factor $1 \alpha(\mathrm{HIF} 1 \alpha)$, estrogen and other growth factors but has not been associated with SphK1 gene translocations or amplifications.

In contrast to SphK1, SPL and SPP expression are variably up- and down-regulated in a variety of different human cancers and murine cancer models. SPL promotes apoptosis through p53- and p38-dependent pathways, whereas SPL gene disruption in mouse embryonic fibroblasts increases their resistance to chemotherapeutic agents by upregulation of Bcl-2 and Bcl-xL ${ }^{87,88}$. SPL is activated by stress and, its upregulation in some cancers may be secondary to the unfavorable conditions of the tumor environment or in response to S1P generation by tumor cells ${ }^{87}$. Whether SPL functions as an anti-oncogene whose inactivation contributes directly to carcinogenesis will require further study.

Pharmacological strategies to prevent tumor progression by inhibiting S1P biosynthesis, increasing its catabolism and modulating receptor signaling appear promising and may add significantly to the armamentarium of adjuvant cancer chemotherapeutics ${ }^{11}$. However, $\mathrm{S} \mathrm{P}_{2}$ knockout mice were recently shown to develop diffuse large B cell lymphomas at a high 
rate, and human diffuse B cell lymphoma samples were found to contain somatic mutations in $\mathrm{S}_{1} \mathrm{P}_{2}{ }^{89}$. Thus, S1P signaling has the potential to act in oncogenic and antioncogenic fashion, raising the possibility that inhibiting S1P signaling could potentially carry a risk of secondary malignancy. In addition, the impact on the immune system of modulating S1P signaling for treatment of cancer or other diseases remains untested. Despite these concerns, targeting S1P signaling seems a propitious new avenue for cancer treatment.

\section{Novel bioactive sphingolipid metabolites (Table 1)}

\section{Ceramide-1-phosphate (C1P)}

In contrast to the pro-apoptotic lipid ceramide, $\mathrm{C} 1 \mathrm{P}$ is a ceramide metabolite that stimulates DNA synthesis and blocks apoptosis in cell cultures (reviewed in ${ }^{90}$ ). Phosphorylation of ceramide at the sn-1 position is mediated by CERK ${ }^{91}$. The C-terminal domain contains a $\mathrm{Ca}^{2+} /$ calmodulin binding motif, and the N-terminal domain contains a pleckstrin homology domain known to bind phosphoinositol-4,5-bisphosphate. CERK is activated by anionic lipids, and cardiolipin functions as a cofactor. Intracellular C1P activates cytosolic phospholipase A2 by increasing its association with the plasma membrane, resulting in increased prostaglandin formation. In addition, CERK is involved in neutrophil phagolysosome formation and mast cell degranulation. Exogenously applied C1P was shown to mediate macrophage migration through activation of a Gi-coupled receptor, leading to downstream activation of ERK1/2 and Akt ${ }^{90,92}$. Recently, a photolabile caged C1P was synthesized, which may help to elucidate C1P-mediated biology and mechanisms of its action ${ }^{93}$.

\section{Ceramide-phosphoethanolamine (CPE)}

Sphingomyelin (SM), the major phosphosphingolipid in mammalian systems, is formed by transfer of a phosphocholine from phosphatidylcholine to ceramide in a reaction catalyzed by SM synthase (SMS) ${ }^{2}$. In insects, the major phosphosphingolipid is ceramidephosphoethanolamine (CPE), formed by CPE synthase activity ${ }^{94}$. Mammalian cells contain a family of SMSs exhibiting different substrate specificities ${ }^{94,95}$. SMS1 resided in the Golgi and catalyzes the formation of SM. SMS2 resides in the plasma membrane, where it catalyzes the formation of both SM and CPE. A SMS-related enzyme (SMSr) resides in the ER of mammalian and insect cells, where it catalyzes the formation of CPE in the ER lumen. In mammalian cells, the cellular content of CPE is several hundred-fold lower than $\mathrm{SM}$. Nevertheless, CPE formed in the SMSr reaction is crucial for normal cell functioning, and blocking this enzymatic step results in increased ER ceramide levels and a defect in the early secretory pathway ${ }^{94}$. Based on this observation, a model in which SMSr functions as a ceramide sensor and regulator has been proposed.

\section{1-deoxy-sphingoid bases}

Fumonisin mycotoxins belonging to the B-series are sphingoid base-like molecules lacking the 1-hydroxyl group. Fumonisin B1 exerts toxicity by inhibiting ceramide synthase. The endogenous compounds 1-deoxy-DHS and its $\mathrm{N}$-acylated form, 1-deoxy-dihydroceramide are similar molecules formed in mammalian cells. These compounds can accumulate to cytotoxic levels due to absence of the 1 hydroxyl group, preventing their conversion to higher order sphingolipids or catabolism through the sphingolipid recycling/degradation pathway. Elevated levels of endogenous 1-deoxy-sphingoid bases occur in patients with hereditary sensory and autonomic neuropathy type 1 (HSAN1) ${ }^{96}$. In HSAN1 patients, a mutation in the Sptlc1 gene encoding a subunit of SPT results in a change in the active site of the enzyme, allowing it to preferentially use L-alanine and L-glycine in lieu of L-serine for the condensation with acyl-CoA, leading to formation of 1-deoxy-DHS and 1deoxmethyl-DHS, respectively. The molecular target of 1-deoxy-DHS and cause of the 
characteristic pain symptomatology of HSAN1 patients remain unknown. However, overexpression of a wild type SPT1 subunit rescues the phenotype of HSAN1 in mouse models ${ }^{96}$. Further, preclinical studies feeding L-serine to HSAN1 mouse models appear promising, indicating the potential of employing a substrate competition strategy to treat HSAN1 patients (Florian Eichler, personal communication).

\section{Sphingadienes}

Unique sphingoid bases differing from sphingosine in the number and position of double bonds, hydroxyl groups and chain-branching have been identified in nature. Sphingadienes, containing two double bonds in the sphingoid base, are found both as free bases and as part of complex sphingolipids in legumes and insects. Soy sphingolipids exert cytotoxic effects on malignant colonic epithelial cell lines and suppress intestinal tumorigenesis in a rodent model of colon cancer ${ }^{97}$. The presence of the sphingadiene backbone appears to be at least partly responsible for this effect ${ }^{98}$. Sphingadienes exert cytotoxicity by preventing Akt translocation from the cytosol to the membrane, thereby reducing protein translation and promoting autophagy and apoptosis ${ }^{98}$. Thus, sphingadienes are being explored for their potential utility in chemoprevention and cancer treatment.

\section{Summary and future perspectives}

New insights regarding sphingolipid-mediated biology emerge each year, and more selective pharmacological agents are continually being identified, rationally designed and tested for treatment of autoimmune disease, cardiovascular disease, cancer, and other conditions, such as the use of the monoclonal S1P antibody iSONEP to treat neovascular age-related macular degeneration. The early results of these studies indicate that we are moving in the right direction, and the potential of modulating S1P and other sphingolipid signaling pathways for therapeutic benefit will be realized.

\section{Acknowledgments}

This work was supported by NIH Public Health Service grants CA77528, CA129438, RAT005336 and GM66954 (JDS). We thank Babak Oskouian for careful review of the manuscript. We apologize to our many colleagues whose work could not be cited due to limitations of space.

\section{Nonstandard abbreviations used}

$\begin{array}{ll}\text { ABC } & \text { ATP-binding cassette } \\ \text { Cer } & \text { ceramide } \\ \text { C1P } & \text { ceramide-1-phosphate } \\ \text { CERK } & \text { ceramide kinase } \\ \text { CIB1 } & \text { calcium and integrin-binding protein 1 } \\ \text { CPE } & \text { ceramidephosphoethanolamine } \\ \text { DHS } & \text { dihydrosphingosine } \\ \text { ER } & \text { endoplasmic reticulum } \\ \text { HDAC } & \text { histone deacetylase } \\ \text { HDL } & \text { high density lipoprotein } \\ \text { HPC } & \text { hematopoietic progenitor cell } \\ \text { ERK } & \text { extracellular signal-regulated kinase }\end{array}$




$\begin{array}{ll}\text { GluCer } & \text { glucosylceramide } \\ \text { HIF } & \text { hypoxia-inducible factor } \\ \text { HSAN1 } & \text { autonomic neuropathy type 1 } \\ \text { I/R } & \text { ischemia/reperfusion } \\ \text { LN } & \text { lymph node } \\ \text { LPP } & \text { lipid phosphate phosphatase } \\ \text { NK } & \text { natural killer } \\ \text { SD } & \text { sphingadiene } \\ \text { So } & \text { sphingosine } \\ \text { S1P } & \text { sphingosine 1-phosphate } \\ \text { SM } & \text { sphingomyelin } \\ \text { SMS } & \text { sphingomyelin synthase } \\ \text { SMSr } & \text { sphingomyelin synthase-related } \\ \text { SphK } & \text { sphingosine kinase } \\ \text { SPL } & \text { sphingosine 1-phosphate lyase } \\ \text { SPP } & \text { sphingosine-1-phosphate phosphatase } \\ \text { SPT } & \text { serine palmitoyltransferase } \\ \text { TCP } & \text { thymic T cell progenitor } \\ \text { THI } & \text { 2-acetyl-4-tetrahydroxybutyl-imidazole }\end{array}$

\section{REFERENCES}

1. Holthuis JC, Pomorski T, Raggers RJ, Sprong H, Van Meer G. The organizing potential of sphingolipids in intracellular membrane transport. Physiol Rev 2001;81:1689-723. [PubMed: 11581500]

2. Merrill, AHJ.; Sandhoff, K. Sphingolipids: metabolism and cell signaling.. In: Vance, DE.; Vance, JE., editors. Biochemistry of Lipids, Lipoproteins and Membranes. Chapter 14; 2002. p. 373-407.

3. Mandala S, et al. Alteration of lymphocyte trafficking by sphingosine-1-phosphate receptor agonists. Science 2002;296:346-9. [PubMed: 11923495]

4. Brinkmann V, et al. The immune modulator FTY720 targets sphingosine 1-phosphate receptors. J Biol Chem 2002;277:21453-7. [PubMed: 11967257]

5. Lahiri S, Futerman A. The metabolism and function of sphingolipids and glycosphingolipids. Cell Mol Life Sci 2007;64:2270-2284. [PubMed: 17558466]

6. Hannun YA, Obeid LM. Principles of bioactive lipid signalling: lessons from sphingolipids. Nat Rev Mol Cell Biol 2008;9:139-50. [PubMed: 18216770]

7. Zheng W, et al. Ceramides and other bioactive sphingolipid backbones in health and disease: lipidomic analysis, metabolism and roles in membrane structure, dynamics, signaling and autophagy. Biochim Biophys Acta 2006;1758:1864-1884. [PubMed: 17052686]

8. Han G, et al. Identification of small subunits of mammalian serine palmitoyltransferase that confer distinct acyl-CoA substrate specificities. Proc Natl Acad Sci U S A 2009;106:8186-91. [PubMed: 19416851]

9. Breslow DK, et al. Orm family proteins mediate sphingolipid homeostasis. Nature 2010;463:104853. [PubMed: 20182505] 
10. Chalfant CE, Spiegel S. Sphingosine 1-phosphate and ceramide 1-phosphate: expanding roles in cell signaling. J Cell Sci 2005;118:4605-12. [PubMed: 16219683]

11. Shida D, Takabe K, Kapitonov D, Milstien S, Spiegel S. Targeting SphK1 as a new strategy against cancer. Curr Drug Targets 2008;9:662-73. [PubMed: 18691013]

12. Pyne S, Lee SC, Long J, Pyne NJ. Role of sphingosine kinases and lipid phosphate phosphatases in regulating spatial sphingosine 1-phosphate signalling in health and disease. Cell Signal 2009;21:14-21. [PubMed: 18768158]

13. Alemany R, van Koppen CJ, Danneberg K, Ter Braak M, Meyer Zu Heringdorf D. Regulation and functional roles of sphingosine kinases. Naunyn Schmiedebergs Arch Pharmacol 2007;374:41328. [PubMed: 17242884]

14. Mizugishi K, et al. Essential role for sphingosine kinases in neural and vascular development. Mol Cell Biol 2005;25:11113-21. [PubMed: 16314531]

15. Gillies L, et al. The sphingosine 1-phosphate receptor 5 and sphingosine kinases 1 and 2 are localised in centrosomes: possible role in regulating cell division. Cell Signal 2009;21:675-84. [PubMed: 19211033]

16. Jarman KE, Moretti PA, Zebol JR, Pitson SM. Translocation of sphingosine kinase 1 to the plasma membrane is mediated by calcium- and integrin-binding protein 1. J Biol Chem 2010;285:483-92. [PubMed: 19854831]

17. Mizugishi K, et al. Maternal disturbance in activated sphingolipid metabolism causes pregnancy loss in mice. J Clin Invest 2007;117:2993-3006. [PubMed: 17885683]

18. Hait NC, et al. Regulation of histone acetylation in the nucleus by sphingosine-1-phosphate. Science 2009;325:1254-7. [PubMed: 19729656]

19. Weigert A, et al. Sphingosine kinase 2 deficient tumor xenografts show impaired growth and fail to polarize macrophages towards an anti-inflammatory phenotype. Int J Cancer 2009;125:2114-21. [PubMed: 19618460]

20. Lai WQ, et al. Distinct roles of sphingosine kinase 1 and 2 in murine collagen-induced arthritis. J Immunol 2009;183:2097-103. [PubMed: 19596980]

21. Wacker BK, Park TS, Gidday JM. Hypoxic preconditioning-induced cerebral ischemic tolerance: role of microvascular sphingosine kinase 2. Stroke 2009;40:3342-8. [PubMed: 19644058]

22. Liu H, et al. Sphingosine kinase type 2 is a putative BH3-Only protein that induces apoptosis. J Biol Chem 2003;278:40330-6. [PubMed: 12835323]

23. Weigert A, et al. Cleavage of sphingosine kinase 2 by caspase- 1 provokes its release from apoptotic cells. Blood. 2010

24. Don AS, Rosen H. A lipid binding domain in sphingosine kinase 2. Biochem Biophys Res Commun 2009;380:87-92. [PubMed: 19168031]

25. Samy ET, et al. Cutting edge: Modulation of intestinal autoimmunity and IL-2 signaling by sphingosine kinase 2 independent of sphingosine 1-phosphate. J Immunol 2007;179:5644-8. [PubMed: 17947634]

26. Pappu R, et al. Promotion of lymphocyte egress into blood and lymph by distinct sources of sphingosine-1-phosphate. Science 2007;316:295-8. [PubMed: 17363629]

27. Sigal YJ, McDermott MI, Morris AJ. Integral membrane lipid phosphatases/phosphotransferases: common structure and diverse functions. Biochem J 2005;387:281-93. [PubMed: 15801912]

28. Brindley DN, Pilquil C. Lipid phosphate phosphatases and signaling. J Lipid Res 2009;50(Suppl):S225-30. [PubMed: 19066402]

29. Kirby RJ, et al. Dynamic regulation of sphingosine-1-phosphate homeostasis during development of mouse metanephric kidney. Am J Physiol Renal Physiol 2009;296:F634-41. [PubMed: 19073640]

30. Giussani P, et al. Sphingosine-1-phosphate phosphohydrolase regulates endoplasmic reticulum-togolgi trafficking of ceramide. Mol Cell Biol 2006;26:5055-5069. [PubMed: 16782891]

31. Peter BF, et al. Role of sphingosine-1-phosphate phosphohydrolase 1 in the regulation of resistance artery tone. Circ Res 2008;103:315-24. [PubMed: 18583713]

32. Mechtcheriakova D, et al. FTY720-phosphate is dephosphorylated by lipid phosphate phosphatase 3. FEBS Lett 2007;581:3063-8. [PubMed: 17555747] 
33. Serra M, Saba JD. Sphingosine 1-phosphate lyase, a key regulator of sphingosine 1-phosphate signaling and function. Adv Enzyme Regul 2010;50:349-62. [PubMed: 19914275]

34. Zhan X, Desiderio DM. Nitroproteins from a human pituitary adenoma tissue discovered with a nitrotyrosine affinity column and tandem mass spectrometry. Anal Biochem 2006;354:279-89. [PubMed: 16777052]

35. Mukhopadhyay D, Howell KS, Riezman H, Capitani G. Identifying key residues of sphinganine-1phosphate lyase for function in vivo and in vitro. J Biol Chem 2008;283:20159-69. [PubMed: 18487605]

36. Vogel P, et al. Incomplete inhibition of sphingosine 1-phosphate lyase modulates immune system function yet prevents early lethality and non-lymphoid lesions. PLoS ONE 2009;4:e4112. [PubMed: 19119317]

37. Hagen N, et al. Subcellular origin of sphingosine-1-phosphate is essental for its toxic effect in lyase deficient neurons. J Biol Chem. 2009

38. Bektas M, et al. S1P lyase deficiency disrupts lipid homeostasis in liver. J Biol Chem. 2010

39. Dobrosotskaya I, Seegmiller A, Brown M, Goldstein J, Rawson R. Regulation of SREBP processing and membrane lipid production by phospholipids in Drosophila. Science 2002;296:879-83. [PubMed: 11988566]

40. Stratford S, Hoehn K, Liu F, Summers S. Regulation of insulin action by ceramide: dual mechanisms linking ceramide accumulation to the inhibition of Akt/protein kinase B. J Biol Chem 2004;279:36608-36615. [PubMed: 15220355]

41. Zhang K, et al. Redirection of sphingolipid metabolism towards de novo synthesis of ethanolamine in Leishmania. EMBO J 2007;26:1094-1104. [PubMed: 17290222]

42. Kono M, Allende ML, Proia RL. Sphingosine-1-phosphate regulation of mammalian development. Biochim Biophys Acta 2008;1781:435-41. [PubMed: 18675379]

43. Choi JW, Lee CW, Chun J. Biological roles of lysophospholipid receptors revealed by genetic null mice: an update. Biochim Biophys Acta 2008;1781:531-9. [PubMed: 18407842]

44. Skoura A, Hla T. Lysophospholipid receptors in vertebrate development, physiology, and pathology. J Lipid Res 2009;50(Suppl):S293-8. [PubMed: 19065000]

45. Strochlic L, Dwivedy A, van Horck FP, Falk J, Holt CE. A role for S1P signalling in axon guidance in the Xenopus visual system. Development 2008;135:333-42. [PubMed: 18077591]

46. Miron VE, et al. Fingolimod (FTY720) Enhances Remyelination Following Demyelination of Organotypic Cerebellar Slices. American Journal of Pathology. 2010

47. Olivera A, et al. Sphingosine kinase 1 and sphingosine-1-phosphate receptor 2 are vital to recovery from anaphylactic shock in mice. J Clin Invest 2010;120:1429-1440. [PubMed: 20407207]

48. Pebay A, et al. Essential roles of sphingosine-1-phosphate and platelet-derived growth factor in the maintenance of human embryonic stem cells. Stem Cells. 2005

49. Bai A, Hu H, Yeung M, Chen J. Kruppel-like factor 2 controls T cell trafficking by activating Lselectin (CD62L) and sphingosine-1-phosphate receptor 1 transcription. J Immunol 2007;178:7632-9. [PubMed: 17548599]

50. Jenne CN, et al. T-bet-dependent S1P5 expression in NK cells promotes egress from lymph nodes and bone marrow. J Exp Med 2009;206:2469-81. [PubMed: 19808259]

51. Sanchez T, Hla T. Structural and functional characteristics of S1P receptors. J Cell Biochem 2004;92:913-22. [PubMed: 15258915]

52. Rosen H, Gonzalez-Cabrera PJ, Sanna MG, Brown S. Sphingosine 1-phosphate receptor signaling. Annu Rev Biochem. 2009

53. Mitra $\mathrm{P}$, et al. Role of ABCC1 in export of sphingosine-1-phosphate from mast cells. Proc Natl Acad Sci U S A 2006;103:16394-9. [PubMed: 17050692]

54. Kobayashi N, Yamaguchi A, Nishi T. Characterization of the ATP-dependent sphingosine 1phosphate transporter in rat erythrocytes. J Biol Chem 2009;284:21192-200. [PubMed: 19531471]

55. Kupperman E, An S, Osborne N, Waldron S, Stainier DY. A sphingosine-1-phosphate receptor regulates cell migration during vertebrate heart development. Nature 2000;406:192-5. [PubMed: 10910360] 
56. Kawahara A, et al. The sphingolipid transporter spns 2 functions in migration of zebrafish myocardial precursors. Science 2009;323:524-7. [PubMed: 19074308]

57. Nakano Y, et al. Mutations in the novel membrane protein spinster interfere with programmed cell death and cause neural degeneration in Drosophila melanogaster. Mol Cell Biol 2001;21:3775-88. [PubMed: 11340170]

58. Hinkovska-Galcheva V, VanWay SM, Shanley TP, Kunkel RG. The role of sphingosine-1phosphate and ceramide-1-phosphate in calcium homeostasis. Curr Opin Investig Drugs 2008;9:1192-205.

59. Estrada R, et al. Ligand-induced nuclear translocation of S1P(1) receptors mediates Cyr61 and CTGF transcription in endothelial cells. Histochem Cell Biol 2009;131:239-49. [PubMed: 18936953]

60. Liao JJ, et al. Distinctive T cell-suppressive signals from nuclearized type 1 sphingosine 1phosphate G protein-coupled receptors. J Biol Chem 2007;282:1964-72. [PubMed: 17121832]

61. Adachi-Yamada T, et al. De novo synthesis of sphingolipids is required for cell survival by downregulating c-Jun N-terminal kinase in Drosophila imaginal discs. Mol Cell Biol 1999;19:7276-86. [PubMed: 10490662]

62. Dasgupta U, et al. Ceramide kinase regulates phospholipase $\mathrm{C}$ and phosphatidylinositol 4, 5, bisphosphate in phototransduction. Proc Natl Acad Sci U S A 2009;106:20063-8. [PubMed: 19892737]

63. Schmahl J, Rizzolo K, Soriano P. The PDGF signaling pathway controls multiple steroidproducing lineages. Genes Dev 2008;22:3255-67. [PubMed: 19056881]

64. Zammit PS, Partridge TA, Yablonka-Reuveni Z. The skeletal muscle satellite cell: the stem cell that came in from the cold. J Histochem Cytochem 2006;54:1177-91. [PubMed: 16899758]

65. Matloubian M, et al. Lymphocyte egress from thymus and peripheral lymphoid organs is dependent on S1P receptor 1. Nature 2004;427:355-60. [PubMed: 14737169]

66. Mandala S, et al. Alteration of lymphocyte trafficking by sphingosine-1-phosphate receptor agonists. Science 2002;296:346-9. [PubMed: 11923495]

67. Rivera J, Proia RL, Olivera A. The alliance of sphingosine-1-phosphate and its receptors in immunity. Nat Rev Immunol 2008;8:753-63. [PubMed: 18787560]

68. Shimizu T. Lipid mediators in health and disease: enzymes and receptors as therapeutic targets for the regulation of immunity and inflammation. Annu Rev Pharmacol Toxicol 2009;49:123-50. [PubMed: 18834304]

69. Schwab SR, Cyster JG. Finding a way out: lymphocyte egress from lymphoid organs. Nat Immunol 2007;8:1295-301. [PubMed: 18026082]

70. Zachariah MA, Cyster JG. Neural Crest-Derived Pericytes Promote Egress of Mature Thymocytes at the Corticomedullary Junction. Science 2010:1-7.

71. Kappos L, et al. A placebo-controlled trial of oral fingolimod in relapsing multiple sclerosis. $\mathrm{N}$ Engl J Med 2010;362:387-401. [PubMed: 20089952]

72. Cohen JA, et al. Oral fingolimod or intramuscular interferon for relapsing multiple sclerosis. $\mathrm{N}$ Engl J Med 2010;362:402-15. [PubMed: 20089954]

73. Ratajczak MZ, et al. Novel insight into stem cell mobilization-Plasma sphingosine-1-phosphate is a major chemoattractant that directs the egress of hematopoietic stem progenitor cells from the bone marrow and its level in peripheral blood increases during mobilization due to activation of complement cascade/membrane attack complex. Leukemia. 2010

74. Gossens K, et al. Thymic progenitor homing and lymphocyte homeostasis are linked via S1Pcontrolled expression of thymic P-selectin/CCL25. J Exp Med 2009;206:761-78. [PubMed: 19289576]

75. Weber C, K.A. Münk A, Bode C, Van Veldhoven PP, Gräler MH. Discontinued postnatal thymocyte development in sphingosine 1-phosphate-lyase-deficient mice. J Immunol 2009;183:4292-4301. [PubMed: 19748984]

76. Ishii M, et al. Sphingosine-1-phosphate mobilizes osteoclast precursors and regulates bone homeostasis. Nature 2009;458:524-8. [PubMed: 19204730]

77. Pereira JP, Cyster JG, Xu Y. A role for S1P and S1P1 in immature-B cell egress from mouse bone marrow. PLoS One 5:e9277. [PubMed: 20174580] 
78. Allende ML, et al. S1P1 receptor directs the release of immature B cells from bone marrow into blood. J Exp Med. 2010

79. Wolf A, et al. The sphingosine 1-phosphate receptor agonist FTY720 potently inhibits regulatory T cell proliferation in vitro and in vivo. J Immunol 2009;183:3751-3760. [PubMed: 19692647]

80. Michaud J, Im D, Hla T. Inhibitory role of sphingosine 1-phosphate receptor 2 in macrophage recruitment during inflammation. J Immunol 2010;184:1475-1483. [PubMed: 20042570]

81. Means C, et al. Sphingosine 1-phosphate S1P2 and S1P3 receptor-mediated Akt activation protects against in vivo myocardial ischemia-reperfusion injury. Am J Physiol Heart Circ Physiol 2007;292:H2944-51. [PubMed: 17293497]

82. Hasegawa Y, Suzuki H, Sozen T, Rolland W, Zhang JH. Activation of sphingosine 1-phosphate receptor-1 by FTY720 is neuroprotective after ischemic stroke in rats. Stroke 2010;41:368-74. [PubMed: 19940275]

83. Morita Y, et al. Oocyte apoptosis is suppressed by disruption of the acid sphingomyelinase gene or by sphingosine-1-phosphate therapy. Nat Med 2000;6:1109-14. [PubMed: 11017141]

84. Sattler K, Levkau B. Sphingosine-1-phosphate as a mediator of high-density lipoprotein effects in cardiovascular protection. Cardiovasc Res 2009;82:201-211. [PubMed: 19233866]

85. Xia P, et al. An oncogenic role of sphingosine kinase. Curr Biol 2000;10:1527-30. [PubMed: 11114522]

86. Visentin B, et al. Validation of an anti-sphingosine-1-phosphate antibody as a potential therapeutic in reducing growth, invasion, and angiogenesis in multiple tumor lineages. Cancer Cell 2006;9:225-238. [PubMed: 16530706]

87. Oskouian B, et al. Sphingosine-1-phosphate lyase potentiates apoptosis via p53- and p38dependent pathways and is downregulated in colon cancer. Proc Natl Acad Sci USA 2006;103:17384-17389. [PubMed: 17090686]

88. Colie S, et al. Disruption of sphingosine 1-phosphate lyase confers resistance to chemotherapy and promotes oncogenesis through Bcl-2/Bcl-xL upregulation. Cancer Res 2009;69:9346-53. [PubMed: 19934311]

89. Cattoretti G, et al. Targeted disruption of the S1P2 sphingosine 1-phosphate receptor gene leads to diffuse large B-cell lymphoma formation. Cancer Res 2009;69:8686-92. [PubMed: 19903857]

90. Levi M, Meijler MM, Gomez-Munoz A, Zor T. Distinct receptor-mediated activities in macrophages for natural ceramide-1-phosphate (C1P) and for phospho-ceramide analogue-1 (PCERA-1). Molecular and Cellular Endocrinology 2010;314:248-55. [PubMed: 19467294]

91. Wijesinghe DS, et al. Substrate specificity of human ceramide kinase. J Lipid Res 2005;46:270616. [PubMed: 16170208]

92. Granado $\mathrm{MH}$, et al. Ceramide 1-phosphate (C1P) promotes cell migration Involvement of a specific C1P receptor. Cell Signal 2009;21:405-12. [PubMed: 19041940]

93. Lankalapalli RS, Ouro A, Arana L, Gomez-Munoz A, Bittman R. Caged ceramide 1-phosphate analogues: synthesis and properties. J Org Chem 2009;74:8844-7. [PubMed: 19908915]

94. Vacaru AM, et al. Sphingomyelin synthase-related protein SMSr controls ceramide homeostasis in the ER. J Cell Biol 2009;185:1013-27. [PubMed: 19506037]

95. Ternes P, Brouwers JF, van den Dikkenberg J, Holthuis JC. Sphingomyelin synthase SMS2 displays dual activity as ceramide phosphoethanolamine synthase. J Lipid Res 2009;50:2270-7. [PubMed: 19454763]

96. Eichler FS, et al. Overexpression of the wild-type SPT1 subunit lowers desoxysphingolipid levels and rescues the phenotype of HSAN1. J Neurosci 2009;29:14646-51. [PubMed: 19923297]

97. Symolon H, Schmelz E, Dillehay D, Merrill AJ. Dietary soy sphingolipids suppress tumorigenesis and gene expression in 1,2-dimethylhydrazine-treated CF1 mice and ApcMin/+ mice. J Nutr 2004;134:1157-1161. [PubMed: 15113963]

98. Fyrst H, et al. Natural sphingadienes inhibit Akt-dependent signaling and prevent intestinal tumorigenesis. Cancer Res 2009;69:9457-64. [PubMed: 19934323]

99. Yamaji T, Kumagai K, Tomishige N, Hanada K. Two sphingolipid transfer proteins, CERT and FAPP2: their roles in sphingolipid metabolism. IUBMB Life 2008;60:511-8. [PubMed: 18459163] 
100. Mao C, Obeid LM. Ceramidases: regulators of cellular responses mediated by ceramide, sphingosine, and sphingosine-1-phosphate. Biochim Biophys Acta 2008;1781:424-34. [PubMed: 18619555] 


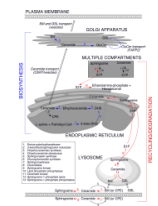

Figure 1. The sphingolipid metabolic pathway

The de novo biosynthesis of sphingolipids initiates in the endoplasmic reticulum (ER) where serine palmitoyltransferase condenses L-serine and palmitoyl-CoA, generating 3-

ketodihydrosphingosine (3-keto-DHS), which is rapidly reduced to form dihydrosphingosine (DHS). DHS is N-acylated to form dihydroceramide, which is further converted into ceramide by the introduction of a double bond in the DHS base. Newly synthesized ceramide is transported to the Golgi apparatus where it is converted to sphingomyelin (SM) and glucosylceramide (GluCer). Ceramide transport to the Golgi is facilitated by CERT as well as vesicular transport ${ }^{99}$. Transfer of GluCer from the cytoplasmic to the luminal side of the Golgi for the synthesis of complex glycosphingolipids (GSL) is facilitated by FAPP2 99 . SM and GSL are transported via vesicles from the Golgi to the plasma membrane. The recycling/degradation of higher order sphingolipids in the plasma membrane or lysosomal compartment also gives rise to ceramide, which can be further deacylated to yield sphingosine ${ }^{100}$. Sphingosine and ceramide can be phosphorylated and de-phosphorylated by kinase and phosphatase activities, which exist in multiple compartments (see text for details). Sphingosine-1-phosphate (S1P) can be irreversibly degraded by S1P lyase located at the cytoplasmic side of the ER. Alternatively, S1P can be de-phosphorylated by specific phosphatases at the luminal side and converted back to ceramide for recycling (salvage pathway). The salvage pathway may also utilize sphingosine exiting directly from the lysosome. SM synthase activity resulting in ceramide-phosphoethanolamine (CPE) formation is found in the plasma membrane and ER. 


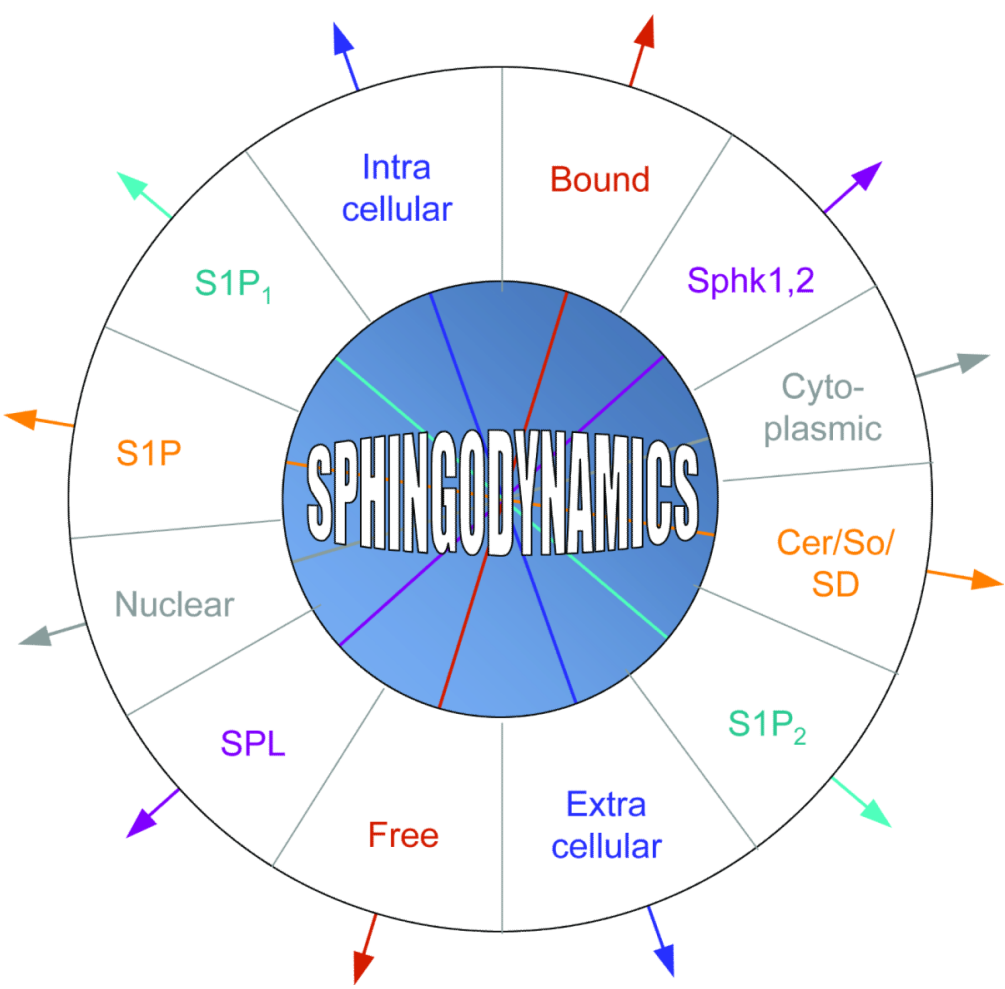

Figure 2. Sphingodynamics

A sphingodynamics model represents the sum of balanced and unbalanced forces exerted upon cells via the interplay between bioactive sphingolipids and their targets in cells, membranes, tissues and circulating fluids. Cer = ceramide; So = sphingosine; $\mathrm{SD}=$ sphingadiene. 
Regulation of spindle formation/mitosis

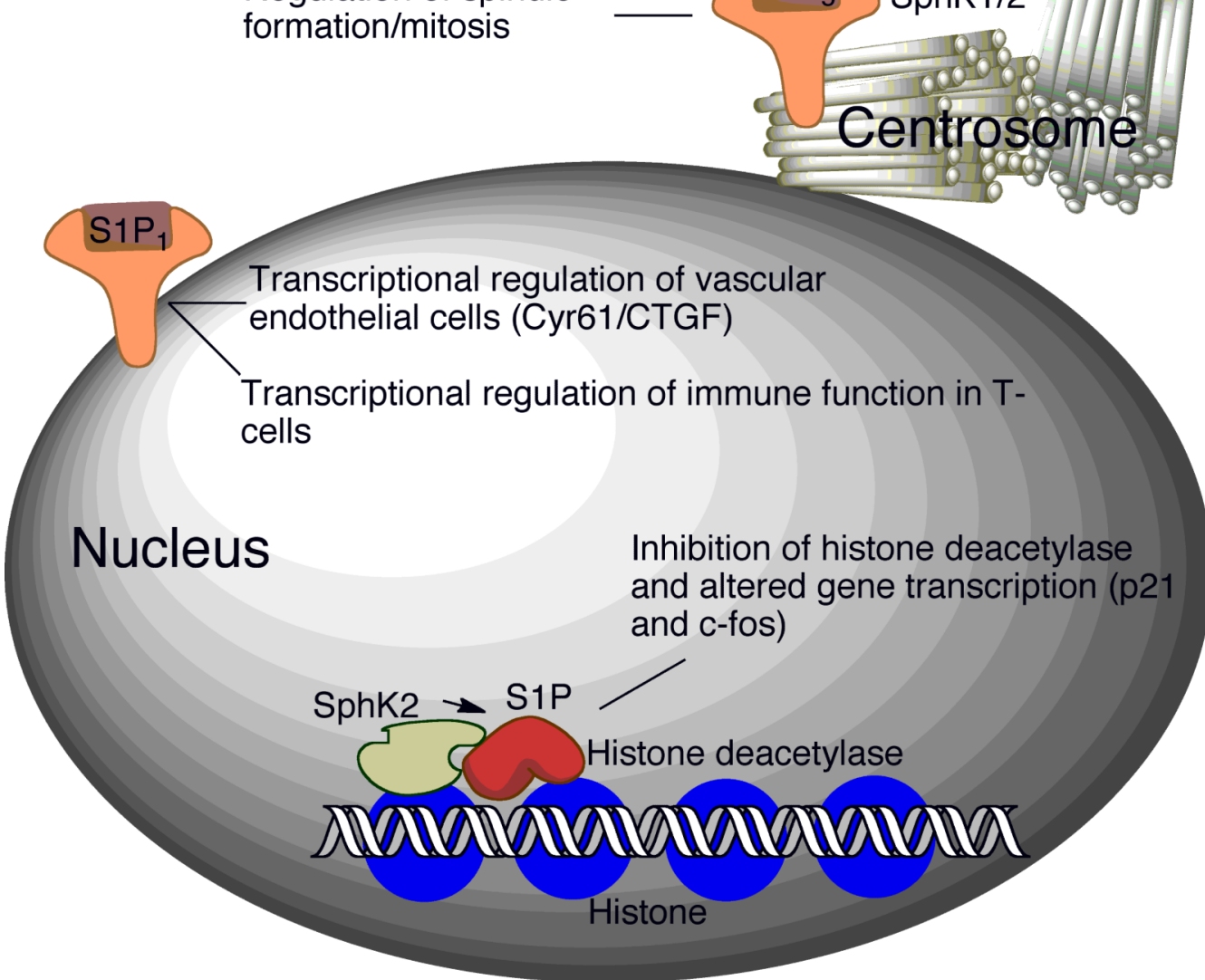

Figure 3. S1P signaling in the nucleus

Recently, nuclear functions of S1P have been revealed. Signaling through nuclear-associated $\mathrm{S}_{1} \mathrm{P}_{1}$ regulates gene transcription in endothelial cells and T-cells, thereby affecting vasculature and immune functions ${ }^{59,60}$. S1P formed by SphK2 inhibits histone deacetylases. Complexes containing SphK2 and histone deacetylases are enriched in the promotor regions of $\mathrm{p} 21$ and c-fos genes ${ }^{18}$. $\mathrm{S} \mathrm{P}_{5}$ and both $\mathrm{SphK}$ isoforms are found within the centrosome, where they have been postulated to play a role in spindle formation and mitosis ${ }^{15}$. 


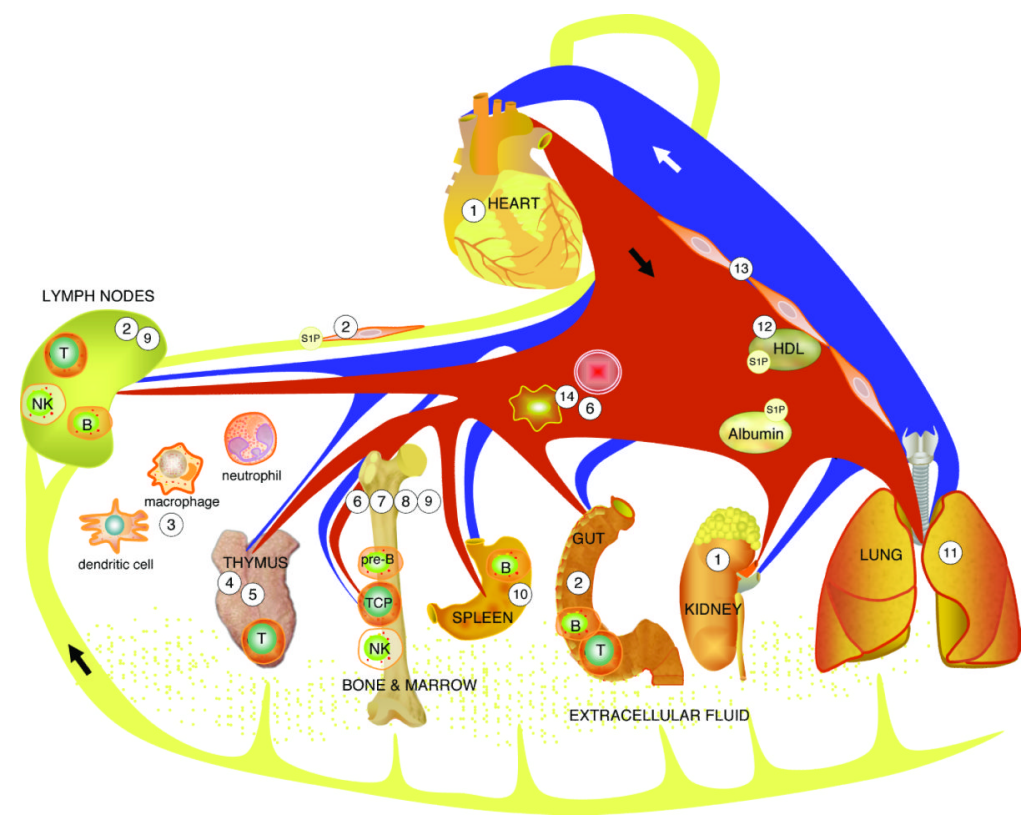

Figure 4. S1P signaling in immunity and tissue injury

S1P signaling contributes to many aspects of innate and adaptive immunity.

Pharmacological modulation of this pathway may attenuate tissue injury from autoimmune diseases, ischemia, sepsis and other conditions. 1) $\mathrm{S} 1 \mathrm{P} / \mathrm{S} 1 \mathrm{P}_{1,2,3}$ mediates cardioprotection. Pharmacological activation of $\mathrm{S}_{1} \mathrm{P}_{1}$ and/or inhibition of SPL protect against cardiac and renal ischemia/reperfusion injury. 2) Lymph S1P is generated by lymphatic endothelium. This S1P source is required for lymphatic patterning and lymphocyte egress from lymph nodes and Peyer's patches. FTY720-phosphate blocks lymphocyte trafficking through functional antagonism and prolonged downregulation of $\left.\mathrm{S}_{1} \mathrm{P}_{1}{ }^{65} 66.3\right) \mathrm{S} 1 \mathrm{P} / \mathrm{S} \mathrm{P}_{2}$ inhibits macrophage migration. S1P signaling contributes to trafficking/effector functions of bone marrow (BM)-derived cells of innate immune system. 4) S1P regulates thymic endothelial $\mathrm{P}$-selectin expression, settling of TCPs and mature $\mathrm{T}$ cell egress at the thymic corticomedullary junction, where pericyte-generated $\mathrm{S} 1 \mathrm{P}$ guides $\mathrm{S}_{1} \mathrm{P}_{1}$-expressing thymocytes into the circulation. 5) SPL in the thymus helps establish S1P chemotactic gradients. 6) Complement activation induces release of S1P from erythrocytes, facilitating hematopoietic progenitor cell egress from BM. 7) S1P/S1P $\mathrm{P}_{1}$ facilitates pre-B cell egress from $\mathrm{BM}$ into the circulation. 8) $\mathrm{S} 1 \mathrm{P} / \mathrm{S}_{1} \mathrm{P}_{1}$ regulates migratory behavior of osteoclast precursors (relevant to pathophysiology of rheumatoid arthritis and osteoporosis). 9) S1P/ $\mathrm{S}_{1,5} \mathrm{P}_{1,5}$ facilitates $\mathrm{NK}$ cell egress from $\mathrm{BM}$ and lymph nodes. 10) $\mathrm{S} 1 \mathrm{P} / \mathrm{S} 1 \mathrm{P}_{1}$ induces marginal zone B cell migration into follicles. 11) S1P/S1P 1 and SPL inhibition reduce endotoxininduced lung injury. 12) HDL-bound S1P may mediate protection from atherosclerosis. 13) $\mathrm{S} 1 \mathrm{P} / \mathrm{S}_{1} \mathrm{P}_{1,2,3}$ regulates vascular permeability and arterial pressure. 14) Erythrocytes and platelets generate blood S1P. 
Table 1

Bioactive metabolites and pharmacological agents.

\begin{tabular}{|c|c|c|c|}
\hline Structure/Name & Mechanism & Functions/Targeting Utility & Reference/Review \\
\hline Sphingosine-1-phosphate & $\begin{array}{l}\text {-Ligand for } \mathrm{G} \text { protein coupled } \\
\text { receptors } \mathrm{S}_{1-5} \\
\text {-Intracellular control of calcium } \\
\text { homeostasis } \\
\text {-Intranuclear regulation of histone } \\
\text { deacetylation }\end{array}$ & $\begin{array}{l}\text {-Survival/ Mitogenesis } \\
\text { - Cell adhesion } \\
\text {-Developmental functions } \\
\text { - Vascular permeability } \\
\text {-Immune cell trafficking } \\
\text {-Angiogenesis } \\
\text { - Cardioprotection } \\
\text { - Carcinogenesis } \\
\text { - Tumor progression } \\
\text { - Antibodies in use for macular degeneration and } \\
\text { cancer } \\
\text { - Sphingosine kinase inhibitors for cancer }\end{array}$ & This manuscript \\
\hline Ceramide-1-phosphate & $\begin{array}{l}\text {-Ligand for G protein coupled } \\
\text { receptor } \\
\text {-Inhibition of acid sphingomyelinase } \\
\text {-Inhibition of serine } \\
\text { palmitoyltransferase } \\
\text {-Activation of cPLA2 }\end{array}$ & $\begin{array}{l}\text {-Survival/DNA synthesis } \\
\text {-Inhibition of apoptosis } \\
\text {-Inflammation } \\
\text {-Eicosanoid synthesis } \\
\text { - Mast cell degranulation } \\
\text { - Neutrophil phagocytosis }\end{array}$ & $(90)$ \\
\hline Ceramide-phosphoethanolamine & - Regulation of ceramide homeostasis & $\begin{array}{l}\text {-Apoptosis } \\
\text {-Early secretory pathway }\end{array}$ & $(94,95)$ \\
\hline Sphingadiene (Soy) & $\begin{array}{l}\text { - Inhibition of Akt translocation/ } \\
\text { signaling }\end{array}$ & $\begin{array}{l}\text {-Apoptosis } \\
\text {-Autophagy } \\
\text {-Chemoprevention }\end{array}$ & (98) \\
\hline 1-deoxy-dihydrosphingosine & - Unknown & $\begin{array}{l}\text {-Neuronal cell death } \\
\text {-HSAN1 disease }\end{array}$ & (96) \\
\hline FTY720 phosphate & - $\mathrm{S} 1 \mathrm{P}$ receptor agonist & $\begin{array}{l}\text {-Lymphocyte trafficking } \\
\text {-Immunomodulation for autoimmune diseases } \\
\text {-Immunomodulation for solid organ transplantation }\end{array}$ & $(67-69)$ \\
\hline $\begin{array}{l}\mathrm{HO}_{\mathrm{THI}} \\
\mathrm{OH}\end{array}$ & $\begin{array}{l}\text { - Inhibition of sphingosine-1- } \\
\text { phosphate lyase }\end{array}$ & $\begin{array}{l}\text { - Lymphocyte trafficking } \\
\text {-Cardioprotection } \\
\text {-Protection from lung injury }\end{array}$ & (33) \\
\hline
\end{tabular}

